\title{
VLDPE Synthesis by Radical Ethylene Polymerization in Tubular Reactors-Negative Factor or Unrealized Opportunities
}

\author{
Ye. Koval ${ }^{1}$, Ye. Skvortsevitch ${ }^{1}$, E. Mayer $^{2}$ \\ ${ }^{1}$ Tomskneftekhim Ltd., Tomsk, Russia \\ ${ }^{2}$ Tomsk Polytechnic University, Tomsk, Russia \\ Email:mea@tnhk.ru
}

Received 2013

\begin{abstract}
This paper presents the results of polymeric deposit analysis in HP recycling system on two ethylene polymerization trains in tubular reactors when using mixed initiation (organic peroxides and oxygen) in the process of various grade production. It is demonstrated that polymers belong to the very low density type (with $\rho$ in 0,860 to $0,900 \mathrm{~g} / \mathrm{cm}^{3}$ range), due to ultra high branching. Consideration is given to known processes of that kind polymer production. There discussed the alternatives of different approaches to special process features found. It is stated that 80-year high pressure PE synthesis history has been keeping potential for the development.
\end{abstract}

Keywords: VLDPE; LDPE Production Process; Tubular Reactor; Mixed Initiation

\section{Introduction}

In the eve of $80^{\text {th }}$ anniversary of the first PE gram production by ICI's [1] employees E. W. Fawcett and B. O. Gibson in March 1933 in the process of HP ethylene polymerization, the polymer comes first in overall production with annual output over 75 million tons[2].

It is significantly due to the development of the various ethylene polymerization processes and copolymerization with other monomers using wide-ranging initiating and catalytic systems. That provided a potentiality to produce polymers with broad variations of molecular structure, molecular weight and molecular-weight distribution and accordingly with various crystal structure, density, mechanical and physical properties, rheology and other physical specifications. That in its turn permitted to convert a polymer in all state-of-the-art processes for thermoplasts for the widest application in different industries, agriculture, medicine, household goods production providing stable market growth.

Summarized classification of the present PE type variety given in Table 1 is provided in encyclopedic publications [3], although without consideration to another unique material such as UHMWPE demonstrating the highest rate of the production growth [4]. Observed property values of the tested samples are also given in this Table 1.

Chronologically the most recent PE type having been intensively developed over last quarter of a century is VLDPE (or ULDPE) belonging by its properties to plastomers and elastomers rather than to thermoplasts.

The paper [5] presents company achievements in the development of this discipline driven by use of various catalytic systems and high alpha olefins. Control of polymer branching, crystal structure, density and heat transfer properties is performed by change of the amount of alpha-olefins or macromer on metallocene catalyst being introduced on the polymerization stage. The products have been commercialized by Dow Chemical, Exxon, Du Pont, however uneconomic production process by solution technology, cost of co-monomers and specific type catalytic systems retard this promising market segment development.

Table 1. Typical properties of different types of $P E$ and deposit stuff.

\begin{tabular}{lcccccc}
\hline \multicolumn{1}{c}{ Property } & HDPE & LDPE & LLDPE & VLDPE & sample «A» & sample «B» \\
\hline Density $\left(\mathrm{g} / \mathrm{cm}^{3}\right)$ & $0,94-0,97$ & $0,91-0,94$ & $0,90-0,94$ & $0,86-0,90$ & 0,864 & 0,896 \\
Degree of crystallinity (\% from density) & $62-82$ & $42-62$ & $34-62$ & $4-34$ & 14,5 & 32,6 \\
Degree of crystallinity (\% from calorimetry) & $55-77$ & $30-54$ & $22-55$ & $0-22$ & 11,8 & 18,6 \\
Melting temperature $\left({ }^{\circ} \mathrm{C}\right)$ & $125-132$ & $98-115$ & $100-125$ & $60-100$ & $21,4 / 44,1$ & $19,2 / 43,9$ \\
Heat of fusion $(\mathrm{cal} / \mathrm{g})$ & $38-53$ & $21-37$ & $15-43$ & $0-15$ & 8,2 & 12,9 \\
\hline
\end{tabular}


Data relating to synthesis of $\mathrm{PE}$ with density about $0,90 \mathrm{~g} / \mathrm{cm}^{3}$ by HP polymerization with use of 3,4dimethyl-3,3-diphenyl as initiator are also known, however polymerization temperature should be 350-360 ${ }^{\circ} \mathrm{C}$, but that is unrealized in industrial processes due to actuation of reactor protection emergency shutdown system at $320{ }^{\circ} \mathrm{C}$ with discharge into open vent system for avoiding thermal ethylene decomposition. Besides, synthesized polymers had very low molecular weight [6].

LDPE production is the slowest-growing one in PE market development structure. But even insignificant growth would result from either large running plant revamp for the purpose of capacity and economical efficiency increase or from shutdown of obsolescent low capacity plants and construction of the novel ones with high unit capacity [7].

\section{The object of study}

Based on the tendencies outlined it would make sense to communicate some peculiarities of LDPE production by tubular process on two Tomskneftekhim's trains Polymir -75 also celebrating the 20 -aniversary of its operation this year. Process improvement history providing capacity increase up to $240 \mathrm{kty}$ is detailed in paper [8], process flow diagram is given on Figure1.

The main effect has been obtained as a result of mixed initiation (oxygen and organic peroxides) introduction and peroxide "cocktail" improvement in accordance with feasible reactor block [9] operation parameters, that provided ethylene conversion increase up to $28,0 \div 28,5 \%$. HP recycle system consists of HPS (high pressure separator) and three-stage returned gas cooling and LMWPE removal system, in each stage there are a PIP heat-exchanger and a separator. HPS each per train is a vertical and cylindrical vessel of 5 cubical meter capacity operating on a principal of gravity "liquid-gas" mixture separations at the following conditions: temperature 230-240 ${ }^{\circ} \mathrm{C}$, pressure $28-30 \mathrm{MPa}$, filling level - up to $25 \%$ of capacity.

HP recycling system inspection on the both trains has shown the following situation - presence of solid deposits of rubber-like consistency and several centimeter thickness on the HPS walls and covers, as it is demonstrated on Figure 2, as well as films of the same type in heatexchangers and separators.

\section{The Polimir Process}

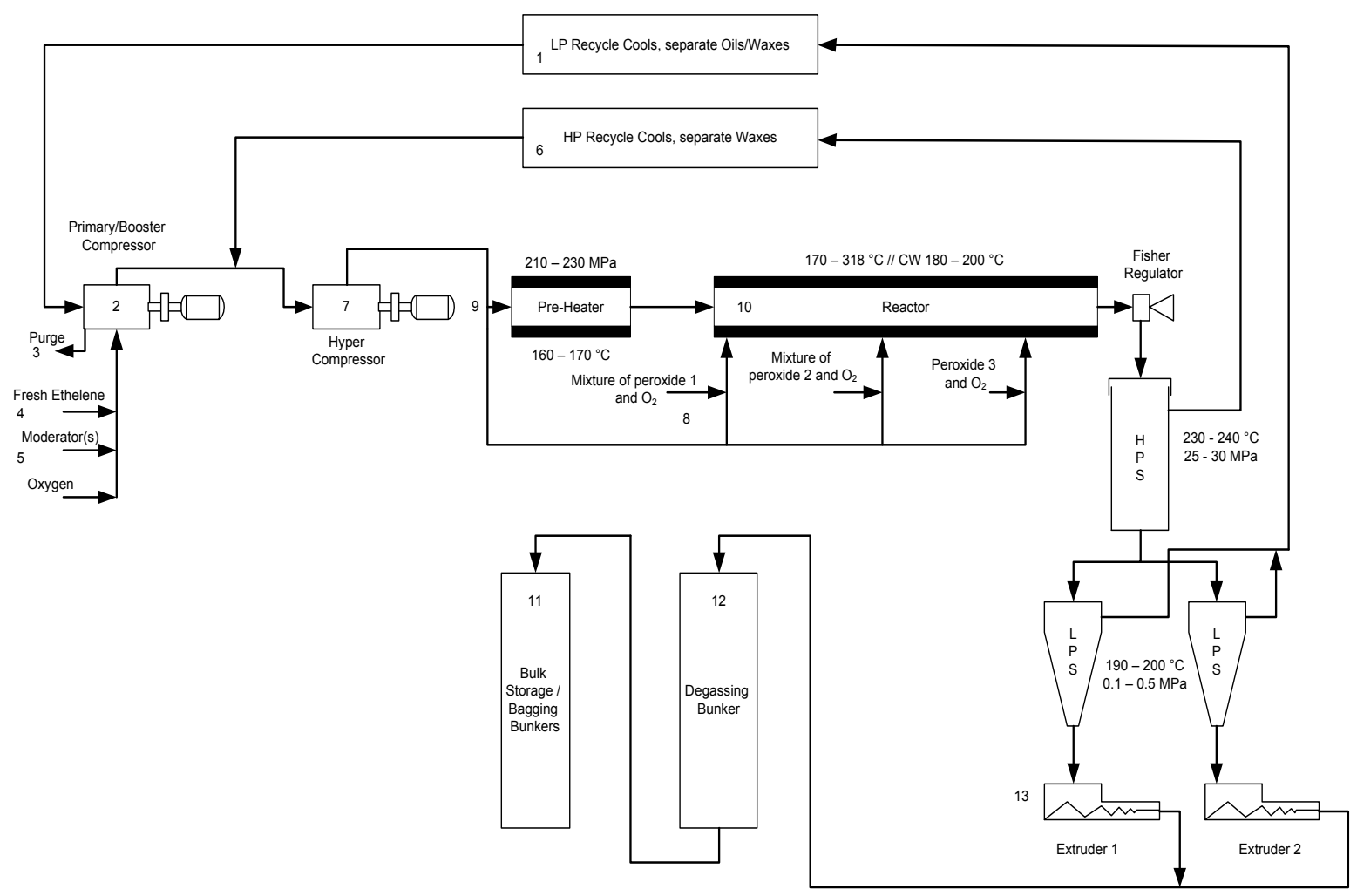

Figure1. LDPE production process in tubular reactor of Tomskneftekhim Ltd. 


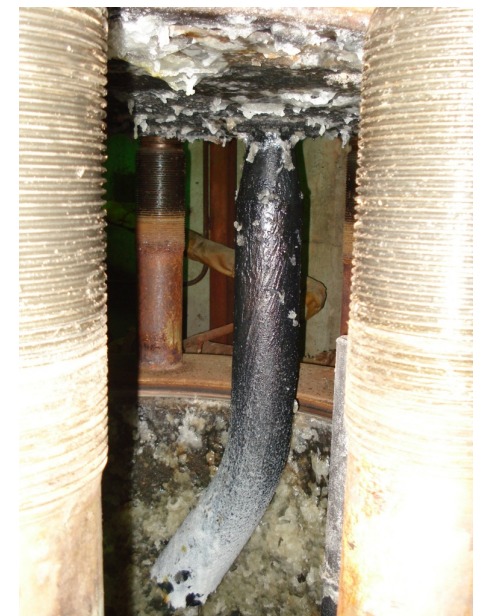

Figure 2. The picture of opened HPS with polymeric deposits on the cover and walls.

Samples taken from HPS for analysis are marked with letters " $A$ " and "B", that corresponds to marking of the polymerization trains (train "A|" is for PE production with MFI 2g/10 min. and train " $\mathrm{B}$ " with MFI 0,3 g/10 $\min )$.

\section{Methods of Analysis}

Polymer density has been measured by flotation method at $25{ }^{\circ} \mathrm{C}$ as per ISO 1183-1:2004, gel fraction measured by selective extraction of soluble portion with hot o-xylol in Soxhlet's (extraction) apparatus in nitrogen, MFI measured as per ISO 1133 on plastometer "Modular Melt Flow Tester" at $190^{\circ} \mathrm{C}$, IR spectra have been taken on films with thickness about $100 \mu \mathrm{m}$ (thickness nonuniformity appeared due to visible sample shrinkage following pressure relief) on spectrometer Avatar 370, calorimetric characteristics have been registered with scanned calorimeter F1 Phoenix, Netzsch in $-60 \mathrm{C}-+200$ temperature range at $10 \mathrm{~g} / \mathrm{min}$ heating-cooling scanning velocity, NMR ${ }^{13} \mathrm{C}$ registered with a device Brucker 400 in trichlorobenzene, crystal structure has been measured with x-ray diffractometer Shimadzu XRD-700.

LDPE industrial samples with MFI $2 \mathrm{~g} / 10 \mathrm{~min}$ and ethylene-propylene-diene terpolymers Royalene 697 and 563 made by Lion Copolymer with mole ratio E/P 70/30 and 56/44 respectively have been analyzed for purpose of comparison.

\section{Findings and Consideration}

Deposits from train "A" have MFI 1,2 g/10 min. and $25 \%$ content of insoluble in o-xylol fraction, from train "B" do 4,1 g/10 min. and $19 \%$ respectively.

Data of IR- Fourier deposit spectroscopy show very high total methyl group content (both end and in branching), $\mathrm{C}-\mathrm{H}$ bond bending absorption band intensity in group $\mathrm{CH}_{3}$ at $1378 \mathrm{~cm}^{-1}$ is more than $720 \mathrm{~cm}^{-1}$ band intensity, characterizing ethylene content. Rough estimate is given as $100 \mathrm{CH}_{3} \backslash 1000 \mathrm{C}$, but typical value for LDPE is about $30 \mathrm{CH}_{3} / 1000 \mathrm{C}$ according to literature data and previously examined sample [10,11], that proves the presence of the reasonable short-chain branch amount.

In paper [12] it is shown by simulation method that 6-7 uniformly embedded propylene links per 100 atoms of $\mathrm{C}$ chain would be enough for producing fully amorphous PE. Propylene as co-monomer is less effective in comparison with high alpha-olefins for decreasing polymer crystallinity. However when producing synthetic ethylene-propylene-diene rubber they practically use $30 \%$ and more of propylene for producing amorphous product due to the lack of ideal co-monomer random distribution - presence of propylene microblocks in a chain. So, for PE amorphicity on the synthesis stage it is required above 300 methyl groups per 1000 atoms of main $\mathrm{C}$ chain.

Deposit sample analysis by $\mathrm{NMR}{ }^{13} \mathrm{C}$ proves the presence of very low intensity signals in $20 \mathrm{ppm}$ area being typical for various stereo-configuration of propylene methyl groups in PE. According to previously made estimates for PE being synthesized in a similar process with use of propylene as a chain transfer agent the portion of methyl groups is not above $2-3 \%$ of the total number of branches $[13,14]$. Therefore, in samples analyzed the major portion of short-chain branches is of different nature. For example, in deposit spectra the proportion of signal intensity of ethyl branches $(8,11 \mathrm{ppm})$ to signal intensity of end and butyl groups is significantly higher rather than in LDPE spectra.

However, known high propylene content ethylene propylene rubbers are convenient samples for comparing the influence of branch number on PE crystal structure. Illustratively on the Fig.3 there are fragments of x-ray spectra (WAXS) of LDPE produced, deposits and ethylene-propylene rubbers with mole propylene content being 30 and $44 \%$ (EPDM- Royalen 697 and Royalen 563). X-ray deposit spectra and EPDM - Royalen 697 are definitely similar and exhibit intensive diffuse scattering in angles $2 \theta$ being typical for crystalline reflexes 100 and 200 of LDPE orthorhombic lattice but differ from PE spectra by the presence of intensive diffuse halo with maxima at $2 \theta$ about $40^{\circ}$. As it was shown before for ethylene copolymers with 1- octene in this area there appeared reflexes of PE hexagonal crystal mesophase [15]. With propylene concentration increase during synthesis there is no hexagonal structuring (Figure 3, fragment EPDM Royalen 563). 
Calorimetric characteristics shown at Figure $\mathbf{4}$ are more informative. For example on "A" deposit melting curve there are two heat-absorbent peaks with maxima $21,4{ }^{\circ} \mathrm{C}$ and $44,1{ }^{\circ} \mathrm{C}$, but on the cooling curve the crystallization peak is $27,4{ }^{\circ} \mathrm{C}$ and subsequent monotonic crystallization. When analyzing " $\mathrm{B}$ " deposits the melt maxima are at $19,2{ }^{\circ} \mathrm{C}$ and $43,9{ }^{\circ} \mathrm{C}$, crystallization peak has maximum at $42,8{ }^{\circ} \mathrm{C}$ and also with subsequent monotonic crystallization. Low temperature maximum enthalpy values are not correct as it is evident that after thermization at $10{ }^{\circ} \mathrm{C}$ and prior to temperature increase the portion of crystallites is in molten state. Thermal characteristics are similar to those described in paper [16] for ethylene-octene copolymer with $0,857 \mathrm{glcm}{ }^{3}$ density, but they differ from data for ultra branching PE with $0,895 \mathrm{~g}^{\mathrm{cm}}{ }^{3}$ density by the lack of high temperature heat-absorbent peak with $\mathrm{T}_{\max }$ about $110{ }^{\circ} \mathrm{C}$.

Similar calorimetric curves for fully amorphous EPDM - Royalen 563 have no crystallization and melting maxima and there observed only glass transition areas and transition to visco-elastic state respectively.

\section{Conclusion}

- It is established that in actual process conditions for ethylene polymerization performance in tubular reactors there are areas with a number of parameters providing high branching PE (VLDPE type) synthesis;

- Routine different MFI PE grade production condition variations permit to change polymer density significantly up to ultra low one;

- Quantitative test of polymeric deposit structure by $\mathrm{NMR}^{13} \mathrm{C}$ spectroscopy and gel-chromatography is required for branch classification, understanding of predominate chain-transfer mechanisms and accordingly those reactor areas where conditions mostly appropriate for this mechanisms realization exist, for example in polymer wall laminar flow as assumed in paper [17];

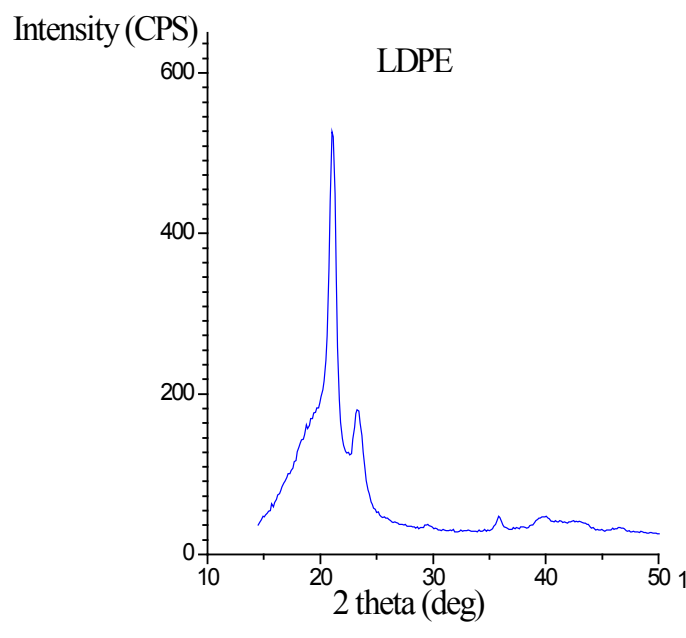

EPDM Royalene 563

EPDM Royalene 697
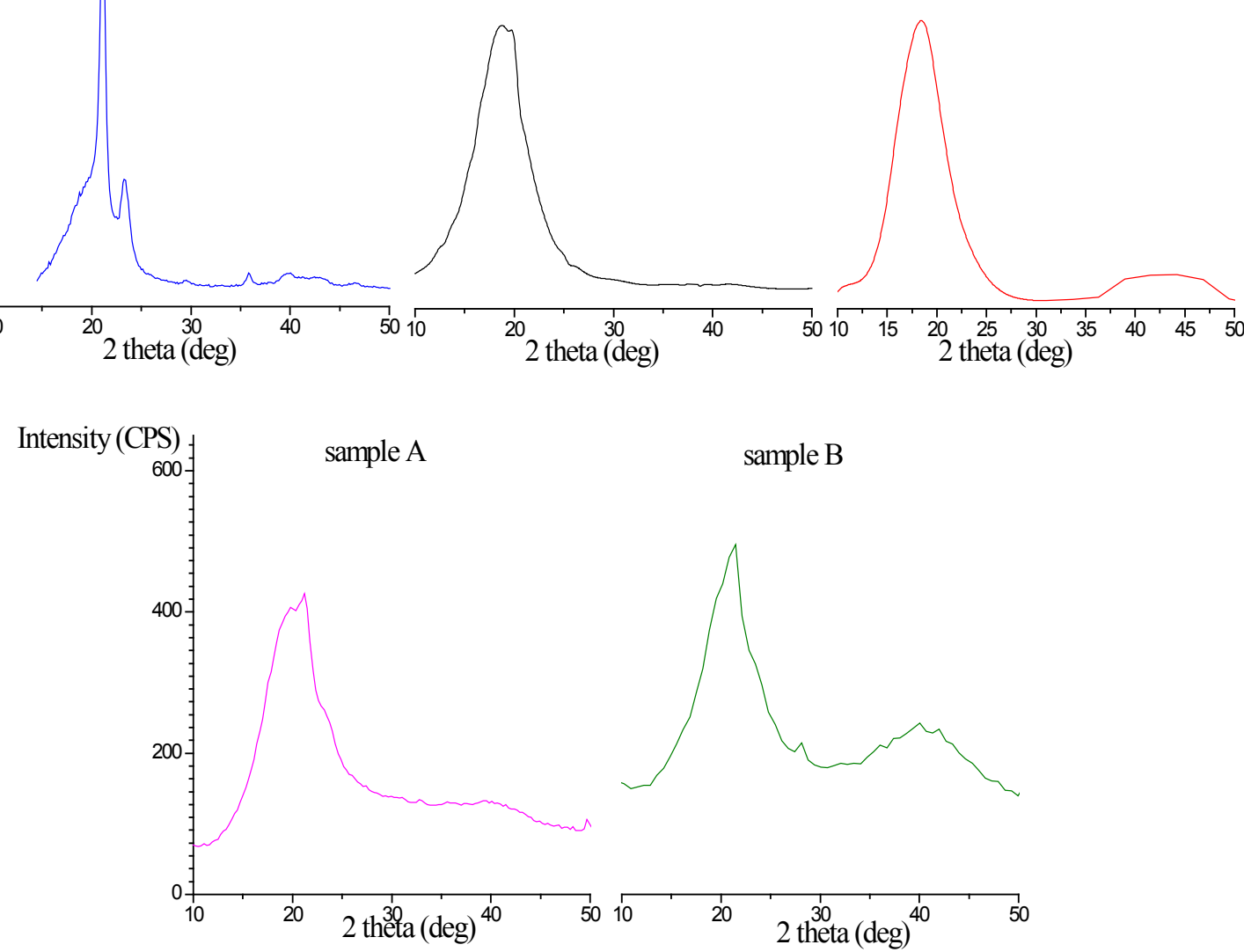

sample B

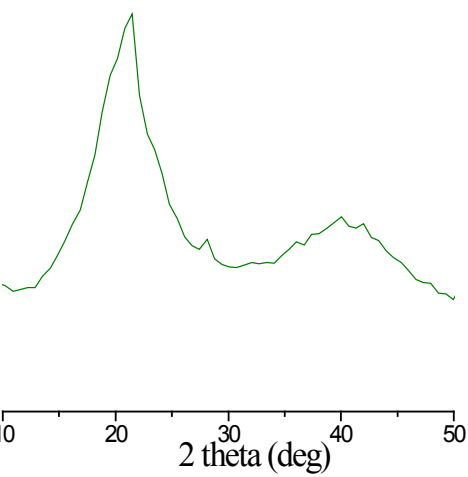

Figure 3. WAXS spectra fragments of samples tested. 


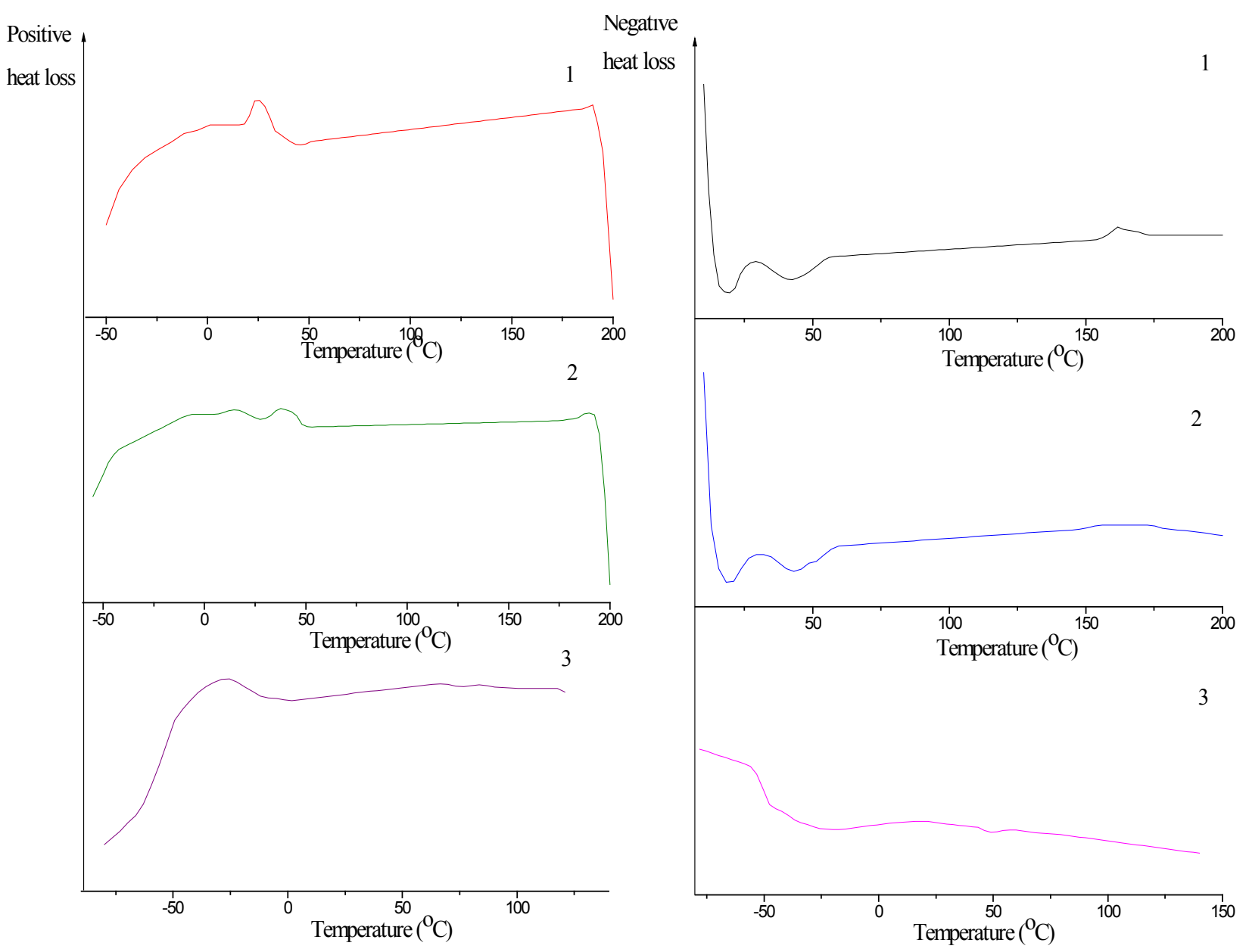

Figure 4. Calorimetric crystallization(left) and melting (right) curves of deposits "A"(1), "B"(2) and EPDM Royalene 563

- This process development for running tubular plants of 5-8 kty capacity could be an alternative for converting into production of high-marginal products;

- Process improvement for the purpose of minimizing such areas at large-scale plants would provide first of all the enhancement of PE physical and mechanical properties as well as HP recycle system operation efficiency.

\section{Acknowledgements}

The authors extend appreciation to professor A. Ozerin and professor S. Chvalun of their involvement into the consideration of results and their consultations.

\section{REFERENCES}

[1] E. Raymond Ellis "Polythene came from Cheshire", Chester, 2005, pp. 11-12.

[2] John N. Bonarius "Strategic Issues In Ethylene and Propylene", Sud-Chemie "Defining the Future ", 23-25 May, 2011, Beijing, China.
[3] Andrew J. Peacock Handbook of Polyethylene. Structures, Properties, and Application $\backslash$ Marcel Dekker, Inc.New-York Basel, 2000, pp. 16.

[4] E.A. Mayer, V.K. Dudchenko, K.M. Kolkov, O.L. Arkatov, V.A. Zakharov, V.E. Nikitin, T.B. Mikenas, "Elaboration and Realisation of Innovative Projects by "Tomskneftekhim" Ltd. and Institute of Catalysis of SB RAS, Russian Journal of Applied Chemistry, Vol. 83, No.3, 2010, pp. 579-582.

[5] Encyclopedia of Polymer Science and Technology, John Wiley and Sons, Inc., Vol. 2, 2008, pp. 441-463.

[6] G. Luft, N. Fischer, M. Dorn, "Radical High Pressure Polymerization of Ethylene with Stabie Initiators", Die Angewandte Makromolekulare Chemie.- 160 (1988), Nr.2616, pp. 193-201.

[7] M. F. Paasen "High Pressure PE Technology", Polyethylene-Polypropylene Chain., MBS., 2009, pp. 125-132.

[8] I. G. Klimov, E. O. Koval, A. N. Pestryakov, E. A. Mayer, "Modernization of "Polimir" process of high-pressure polyethylene production at "Tomskneftekhim" Company", Advanced Materials Research, Vols. 560-561, 2012, pp. 842-845.

[9] Klimov I.G., Mayer E.A., Vlasov A.V., Koval E.O, Pe- 
trenko P.V, Kondratyev Yu.N., Shtamm S.B., "Ethylene polymerization method" RF Patent № 2447088 dd 10.04.2012, priority on $\quad 01.07 .2010$.

[10] A. L. Goldenberg, S. G. Lyubetsky, "Comparative spectrum study of unsaturation in polyethylene" Vysokomolekulyarnye soedinenya, Vol. 5, No 6, 1963, pp. 905-909.

[11] I. G. Klimov, E. O. Koval, A. I. Agafonova, Y. N. Kondratev, E. A. Mayer, "Comparing the influence of the manufacturing process employed on the structure and properties of low-density polyethylene", International Polymer Science and Technology, Vol. 38, No.11, 2011, pp. 21-25.

[12] A. D. Kalashnikov, N. K. Balabaev, E. F. Oleinik, "Structural disturbance within orthorhombic crystal of

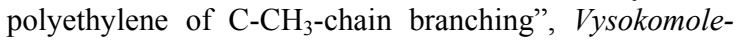
kulyarnye soedinenya, Series A, Vol. 47, No 10, 2005, pp. 1767-1781.

[13] James C. Randall A "Review of High Resolution Liquid 13 Carbon Nuclear Magnetic Resonance Characterizations of Ethylene-Based Polymers", JMS-REV. MACROMOL. CHEM. PHYS., C.29 (2-3). P. 297-303 (1989).

[14] Takao Usami "Fine-Branching Structure in High-Pressure, Low-Density Polyethylenes by $50.10-\mathrm{MHz}{ }^{13} \mathrm{C}$ NMR Analysis", Macromolecules, 17, 1984, pp. 1756-1761.

[15] R. Androsch, J. Blackwell, S. N. Chvalun, B. Wunderlich, "Wide- and Small-Angle X-ray Analysis of Polyethylene-co-octene", Macromolecules, 32, 1999, pp. 3735-3740.

[16] V. I. Selikhov, V. M. Neverov, E. A. Sinevich, V. S. Tikhomirov , "Chvalun S.N., Changing of structure and properties of ethylene/1-octane copolymers and hyperbranched low-density polyethylene under ionization radiation", Vysokomolekulyarnye soedinenya, Series A, Vol. 47, No 2, 2005, pp. 228-241.

[17] G. Eckhardt, E. Brauer, H. J. Meinke, "Zum extreme hochmolekularen Anteil in Hochdruckpolyethylenen aus dem Rohrreaktor III", Plaste und Kautschuk., 32, No.9, 1985, pp. 334-336. 